\title{
Erratum to: A numerical method for determining the stuck point in extended reach drilling
}

(C) China University of Petroleum (Beijing) and Springer-Verlag Berlin Heidelberg 2011

Erratum to: Petroleum Science 2011. 8(3): 345-352.

DOI 10.1007/s12182-011-0151-z

The original version of this article unfortunately contained a mistake in Eq. (14). The correct version is as follows:

$w_{\mathrm{c}}=\frac{\sqrt{\left(F_{\mathrm{e}} k+\tau^{2} E I k+w_{\mathrm{bp}} n_{z}-\tau k M_{\mathrm{t}}\right)^{2}+\left[w_{\mathrm{bp}} b_{z}-\left(2 \tau E I-M_{\mathrm{t}}\right) \frac{\mathrm{d} k}{\mathrm{~d} s}\right]^{2}}}{\sqrt{1+\mu_{\mathrm{t}}^{2}+\tau^{2} \mu_{\mathrm{d}}^{2} r_{\mathrm{o}}^{2}+2 \mu_{\mathrm{t}} \mu_{\mathrm{d}} r_{\mathrm{o}} \tau}}$

The online version of the original article can be found at http://dx.doi.org/10.1007/s12182-011-0151-z. 